Portland State University

PDXScholar

2-1-2021

\title{
The Hot Cracking Susceptibility Subjected the Laser Beam Oscillation Welding on 6XXX Aluminum Alloy with a Partial Penetration Joint
}

\author{
Minjung Kang \\ Korea Institute of Industrial Technology \\ Jason Cheon \\ Korea Institute of Industrial Technology \\ Dong Hyuck Kam \\ Korea Institute of Industrial Technology \\ Cheolhee Kim \\ Portland State University, cheol@pdx.edu
}

Follow this and additional works at: https://pdxscholar.library.pdx.edu/mengin_fac

Part of the Materials Science and Engineering Commons

Let us know how access to this document benefits you.

\section{Citation Details}

Kang, M., Cheon, J., Kam, D. H., \& Kim, C. (2021). The hot cracking susceptibility subjected the laser beam oscillation welding on 6XXX aluminum alloy with a partial penetration joint. Journal of Laser Applications, 33(1), 012032. https://doi.org/10.2351/7.0000319

This Article is brought to you for free and open access. It has been accepted for inclusion in Mechanical and Materials Engineering Faculty Publications and Presentations by an authorized administrator of PDXScholar. Please contact us if we can make this document more accessible: pdxscholar@pdx.edu. 


\section{The hot cracking susceptibility subjected the laser beam oscillation welding on 6XXX aluminum alloy with a partial penetration joint}

Cite as: J. Laser Appl. 33, 012032 (2021); https://doi.org/10.2351/7.0000319

Submitted: 30 November 2020 . Accepted: 30 November 2020 . Published Online: 29 December 2020

(D) Minjung Kang, (D) Jason Cheon, (D) Dong Hyuck Kam, and (D) Cheolhee Kim

COLLECTIONS

Paper published as part of the special topic on Proceedings of the International Congress of Applications of Lasers \& Electro-Optics (ICALEO ${ }^{\circledR}$ 2020)
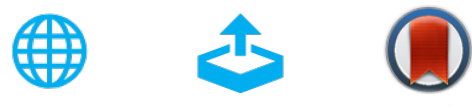

\section{ARTICLES YOU MAY BE INTERESTED IN}

In situ observation with $\mathrm{x}$-ray for tentative exploration of laser beam welding processes for aluminum-based alloys

Journal of Laser Applications 33, 012026 (2021); https://doi.org/10.2351/7.0000315

Applying optical coherence tomography for weld depth monitoring in remote laser welding of automotive battery tab connectors

Journal of Laser Applications 33, 012028 (2021); https://doi.org/10.2351/7.0000336

Correlation of optical signal during laser fusion welding of copper to aluminum

Journal of Laser Applications 33, 012037 (2021); https://doi.org/10.2351/7.0000314

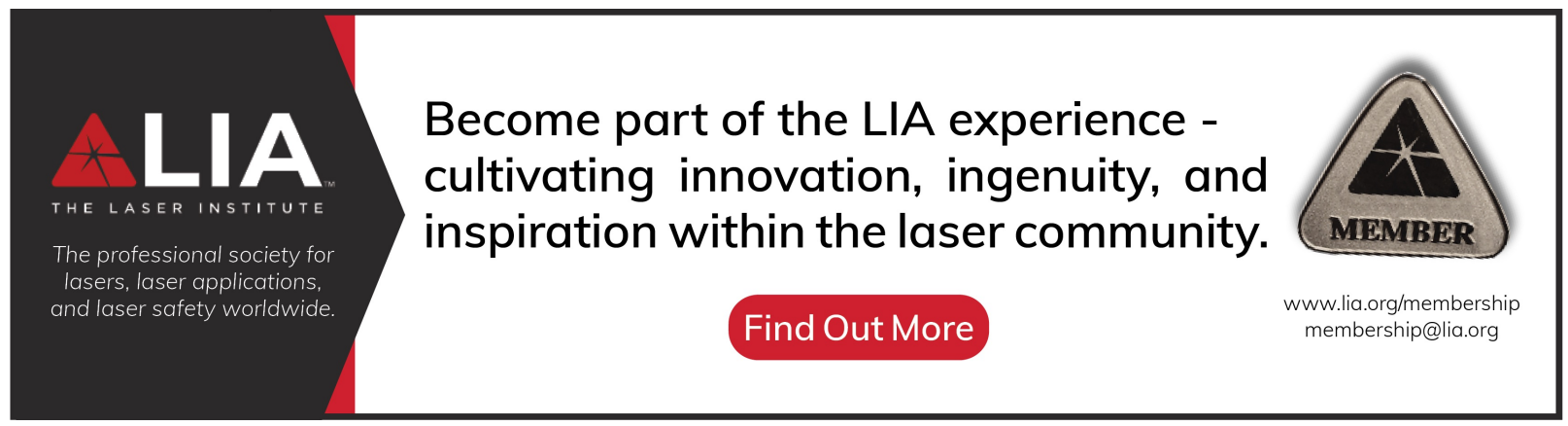

Become part of the LIA experience cultivating innovation, ingenuity, and inspiration within the laser community. 


\title{
The hot cracking susceptibility subjected the laser beam oscillation welding on 6XXX aluminum alloy with a partial penetration joint
}

Cite as: J. Laser Appl. 33, 012032 (2021); doi: 10.2351/7.0000319

Submitted: 30 November 2020 . Accepted: 30 November 2020 .

Published Online: 29 December 2020

Minjung Kang, ${ }^{7}$ (i) Jason Cheon, ${ }^{\text {[D }}$ Dong Hyuck Kam, ${ }^{7}$ (D) and Cheolhee Kim ${ }^{1,2}$ (D)

\section{AFFILIATIONS}

1Joining Research Group, Korea Institute of Industrial Technology, 156 Gatbeol-ro, Incheon 21999, Korea

${ }^{2}$ Department of Mechanical and Materials Engineering, Portland State University, Portland, Oregon 97201

Note: Paper published as part of the special topic on Proceedings of the International Congress of Applications of Lasers \& Electro-Optics 2020.

\begin{abstract}
A laser beam oscillation method using Galvano mirrors, which allows wide weld beads and controls thermal stress distribution, was suggested to suppress the formation of solidification cracks in laser welds. In order to understand the solidification cracking behavior in relation to the bead shape, laser beam oscillation welding was performed under various oscillation widths and frequency conditions. To evaluate the effect of the oscillation parameter on solidification cracking susceptibility, a regression analysis based on the shape of the bead was performed. Stress distribution generated during the laser beam oscillation welding process was also analyzed using finite element modeling simulation. From the results, it was demonstrated that a high shrinkage stress field at the bottom of the partial penetrated bead suppresses the solidification cracking.
\end{abstract}

Key words: laser welding, lap fillet joint, finite element modeling, hot cracking susceptibility, stress distribution

Published under license by Laser Institute of America. https://doi.org/10.2351/7.0000319

\section{INTRODUCTION}

The laser welding of aluminum alloys, such as $2 \mathrm{XXX},{ }^{1}$ $6 \mathrm{XXX},{ }^{2-4}$ and $7 \mathrm{XXX},{ }^{5}$ has limitations due to weld defects such as solidification cracks. Optimization of the weld composition using a filler metal is the conventional method used to prevent solidification cracking. ${ }^{6}$ In order to control the chemical composition of the weld metal, it is necessary to readjust the chemical composition of the aluminum base metal or to add auxiliary filler wire.

Many studies have attempted to suppress the formation of solidification cracks during laser welding by oscillating the laser beam and controlling the laser power with pulse waveforms. The effects of oscillating a heat source on microstructural evolution, ${ }^{7}$ solidification crack susceptibility, ${ }^{8}$ and welding strength ${ }^{9}$ have been investigated. Choi et al. ${ }^{10}$ applied a low-frequency laser oscillation on the $6 \mathrm{~K} 21 \mathrm{Al}$ alloy to improve its joint strength. Notably, oscillation of the heat source changed the shape of the weld beads and solidification morphology ${ }^{11}$ obtained through columnar and equiaxed dendritic growth.
Determining the behaviors of heat transfer and stress distribution around the molten pool are important to understand hot cracking formation. In laser welding, the high density of the focused laser beam was irradiated onto the substrate, and complex phenomena such as the temperature dependency of the material properties' phase transition (i.e., melting and evaporation) occurred in a short time. Numerical simulation of the welding process has been a major topic in welding research for several years. The results of simulations can be used to explain the physical essence of some complex phenomena in the welding process. The simulation of the laser welding process enables the estimation of transient stresses, residual stresses, and distortions. These can be used to evaluate structural misalignments and unexpected failures due to overstressing. ${ }^{12}$ A number of numerical simulations for laser welding processes have been conducted to evaluate temperature and stress distribution and predict the residual stress and final distortions of structural components. ${ }^{13,14}$

The aim of this study is to investigate the influence of highfrequency beam oscillations on the hot cracking susceptibility and 
TABLE I. Chemical compositions measured with inductively coupled plasma and mechanical properties of applied base material.

\begin{tabular}{|c|c|c|c|c|c|c|c|c|}
\hline \multicolumn{9}{|c|}{ Chemical compositions (wt. \%) } \\
\hline $\mathrm{Si}$ & $\mathrm{Fe}$ & $\mathrm{Cu}$ & $\mathrm{Mn}$ & $\mathrm{Mg}$ & $\mathrm{Cr}$ & $\mathrm{Zn}$ & $\mathrm{Ti}$ & $\mathrm{Al}$ \\
\hline 0.58 & 0.21 & 0.14 & 0.08 & 0.64 & 0.01 & 0.01 & 0.03 & Bal \\
\hline \multicolumn{9}{|c|}{ Mechanical properties } \\
\hline \multicolumn{3}{|c|}{$\begin{array}{l}\text { Tensile strength } \\
(\mathrm{MPa})\end{array}$} & \multicolumn{3}{|c|}{$\begin{array}{l}\text { Yield strength }{ }^{\mathrm{a}} \\
(\mathrm{MPa})\end{array}$} & \multicolumn{3}{|c|}{$\begin{array}{l}\text { Elongation at } \\
\text { fracture }^{\mathrm{a}}(\%)\end{array}$} \\
\hline \multicolumn{3}{|l|}{234} & \multicolumn{3}{|c|}{126} & \multicolumn{3}{|c|}{24} \\
\hline
\end{tabular}

${ }^{\mathrm{a}}$ Averaged using three quasistatic tensile tests.

the bead appearance of aluminum alloy with a filet joint. A comparison of the hot cracking length of welds showed that beam oscillation did reduce the hot cracking susceptibility. Considerable heterogeneity in stress distribution was calculated across the weld joint in the numerical simulation results due to the strong compressed stress at the bottom of the specimen during laser beam oscillation.

\section{EXPERIMENTAL SETUP}

For the welding process, a continuous-mode fiber laser, YLS-3000 (IPG Photonics, Oxford, MA, USA), was applied and delivered through a two-axis scanner, D30 (IPG Photonics, Oxford, MA, USA), with a focal length of $250 \mathrm{~mm}$. The laser beam was perpendicularly irradiated to the specimen and was focused on the upper surface of the workpiece with a beam diameter of $0.28 \mathrm{~mm}$. Ar shielding gas was provided to the side during welding. The base material was a $1 \mathrm{~mm}$-thick of $\mathrm{Al}$ 6014-T4 alloy. Chemical compositions and mechanical properties are presented in Table I. In this study, circular patterns were adopted and compared with general linear motion. In order to evaluate the effect of welding parameters on hot crack susceptibility, the oscillation width and frequency were varied.

To evaluate the hot cracking susceptibility of lap joint welds, a modified self-restraint test specimen was adapted, as shown in Fig. 1. During the laser welding, tensile and rotational stress were generated near the fusion zone [Fig. 2(a)], ${ }^{15}$ and finally formed a

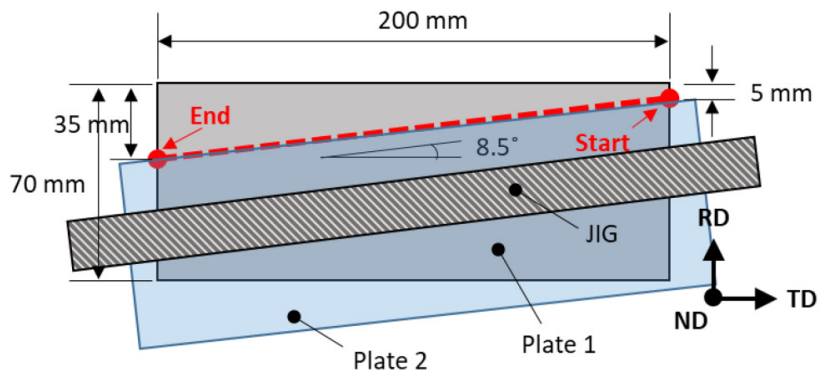

FIG. 1. Schematic image of specimen applied hot cracking susceptibility testing.

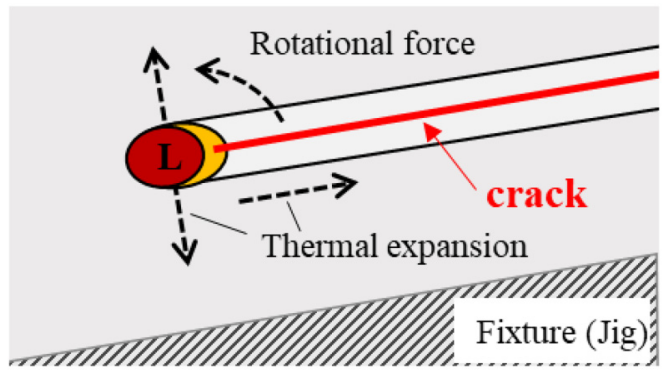

(a)

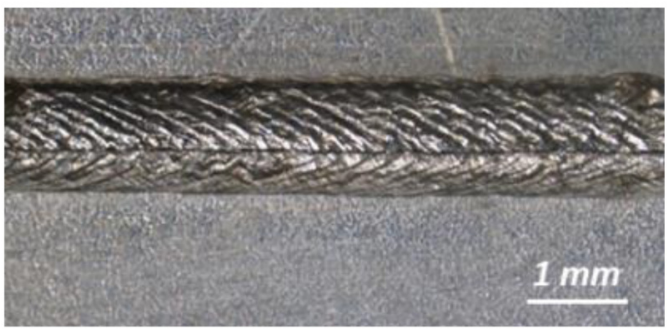

(b)

FIG. 2. (a) Schematic images of active force during the laser welding, and (b) crack generated at the center of a lap filet joint.

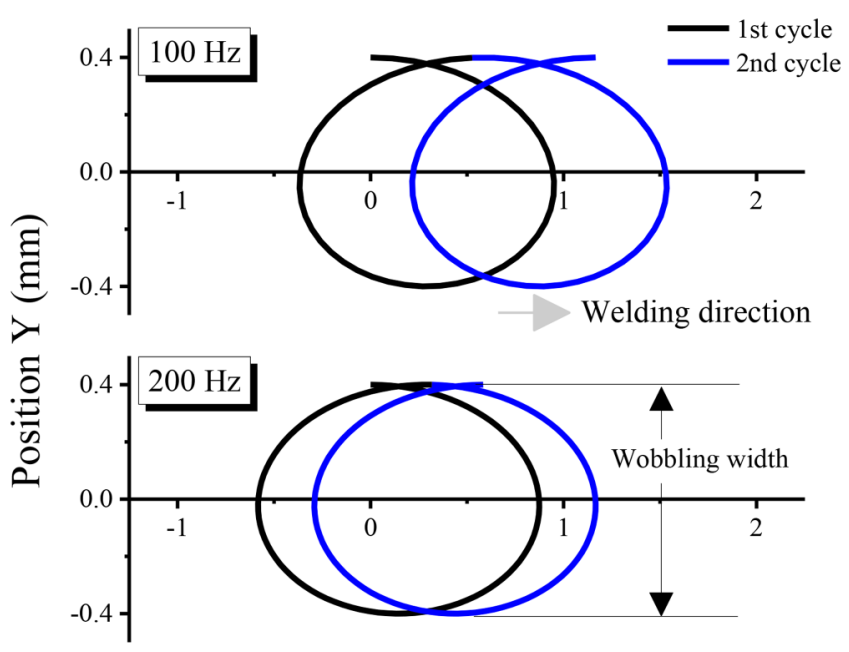

\section{Position X (mm)}

FIG. 3. Laser beam patterns oscillated circularly at a welding speed of $3 \mathrm{~m} / \mathrm{min}$, with an oscillation width of $0.8 \mathrm{~mm}$ and oscillation frequency of (a) 100 and (b) $200 \mathrm{~Hz}$. 
TABLE II. Laser welding conditions used in experiments.

\begin{tabular}{cc}
\hline \hline Laser power $(\mathrm{W})$ & 2300 \\
Welding speed $(\mathrm{mm} / \mathrm{s})$ & 50 \\
Oscillation width $(\mathrm{mm})$ & $0,0.2,0.4,0.8,1.6$ \\
Oscillation frequency $(\mathrm{Hz})$ & $0,100,200,400$ \\
Focal position $(\mathrm{mm})$ & 0 (on upper sheet) \\
Offset $(\mathrm{mm})$ & 0 \\
Beam tilting angle $\left(^{\circ}\right)$ & 0 \\
Beam pattern & Circle \\
Shielding gas & Ar shielding \\
\hline \hline
\end{tabular}

solidification crack at the center of the weld bead [Fig. 2(b)]. Figure 3 shows the laser beam path for the circular beam patterns at different frequencies at 100 and $200 \mathrm{~Hz}$, respectively. The laser power and welding speed were fixed as $2300 \mathrm{~W}$ and $3 \mathrm{~m} / \mathrm{min}$, respectively. The laser beam was subjected to the edge of the upper plate and started at the narrow edge and ended at the wide edge. The details of the laser welding conditions are presented in Table II.

After welding, a nondestructive $\mathrm{x}$-ray test was conducted to measure the hot cracking length using XSCAN-H160 (XAVIS,

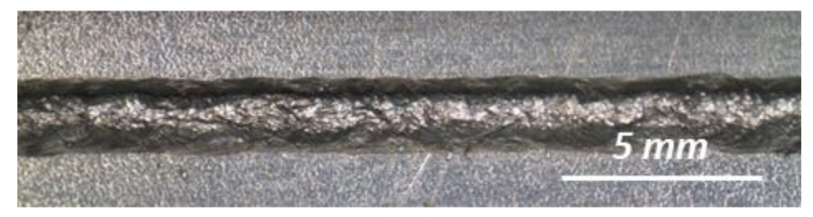

(a)

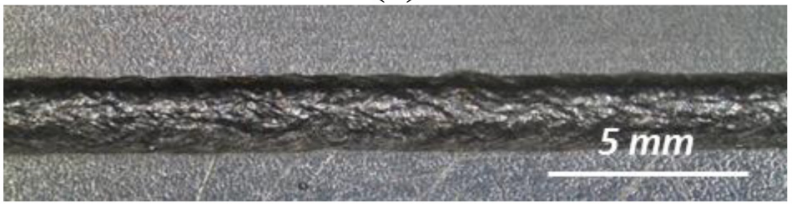

(b)

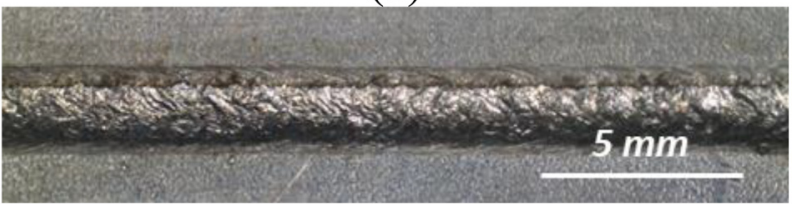

(c)

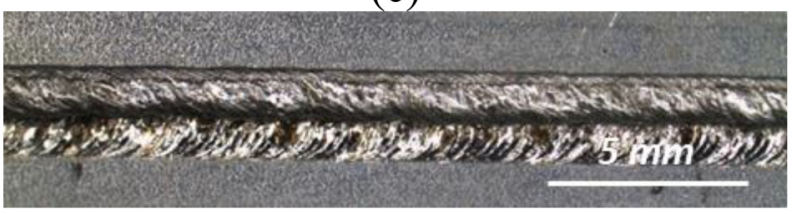

(d)

FIG. 4. Bead appearance under various oscillation width conditions of (a) 0.2 , (b) 0.4 , (c) 0.8 , and (d) $1.6 \mathrm{~mm}$. Specimens were fabricated at an oscillation frequency of $200 \mathrm{~Hz}$ under a laser power of $2300 \mathrm{~W}$ and welding speed of $50 \mathrm{~mm} / \mathrm{s}$.
Seongnam, Gyeonggi, Korea). The surface of the samples was polished and etched with Keller's etchant. To characterize the effect of bead shape on cracking, the section of welds was observed in two separate samples.

\section{RESULTS AND DISCUSSION}

\section{A. Influence of laser beam oscillation on bead appearance and hot cracking susceptibility}

Laser beam oscillation is beneficial to obtain a smooth bead appearance. This means that oscillation width and frequency affect the bead appearance. As the oscillation width increased, the edge near the fusion line became smooth [Fig. 4(c)], while an undercut was found in narrow oscillation cases, as shown in Figs. 4(a) and 4(b). However, when the oscillation width was wider than the critical width, the joint did not melt sufficiently due to the lack of heat input.

Figure 5 shows sectional images of the specimens according to oscillation frequency. To evaluate the effect of oscillation on bead appearance, factors derived from sectional images were defined and named $a_{1}$ to $a_{5}$ and $s_{1}$. As shown in Fig. 5(a), bead width at the interface is $a_{1}$, bead width at the top surface is $a_{2}$, the thickness of the throat is $a_{3}$, the bead width at the bottom surface is $a_{4}$, the

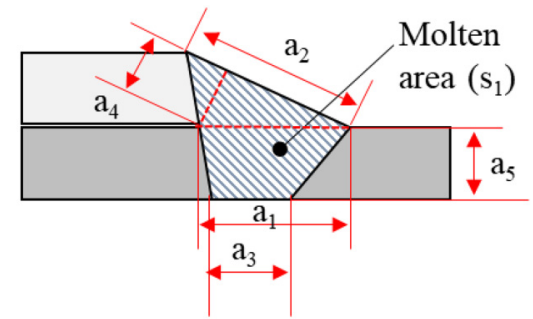

(a)

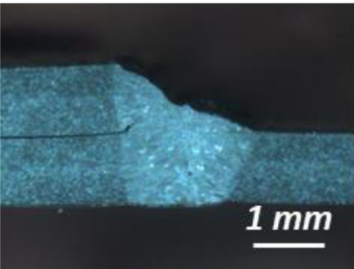

(b)

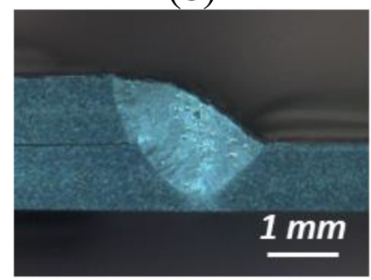

(d)

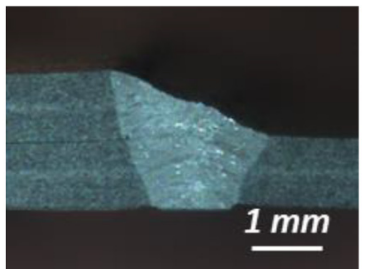

(c)

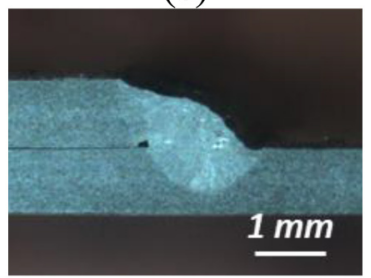

(e)
FIG. 5. Definition of geometrical factor (a) and macrosectional images for various oscillation frequencies of (b) 0 , (c) 100 , (d) 200 , and (e) $300 \mathrm{~Hz}$. Oscillation width was fixed at $0.8 \mathrm{~mm}$. 


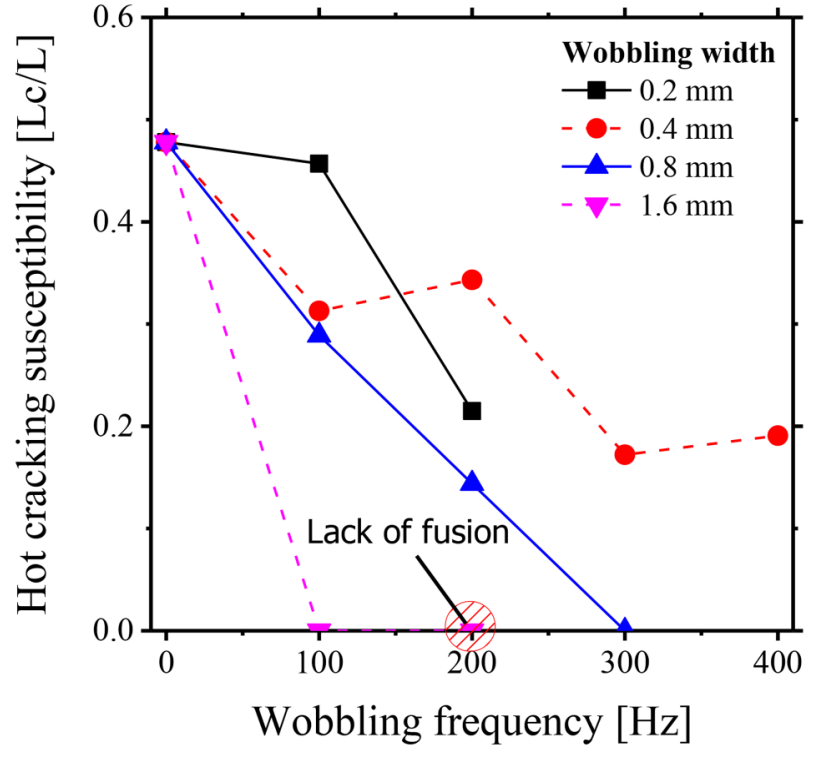

FIG. 6. Hot cracking susceptibility depending on oscillation width and frequency.

penetration depth is $a_{5}$, and the molten area is $s_{1}$. Compared to linear welding [Fig. 5(a)], the bead width at the bottom surface $\left(a_{3}\right)$ decreased and the depth of the bead $\left(a_{5}\right)$ became shallower when using oscillating laser beams. The full penetration weld beads were obtained at small oscillation width and frequency condition.

The laser beam oscillation also affected the hot cracking behavior. In the present study, hot cracking susceptibility was defined as the ratio of the crack length to the entire weld length. Cracking was generally initiated and propagated along the welding trajectory. The length of cracks were measured using a nondestructive $\mathrm{x}$ ray and are presented in Fig. 6. Hot cracking susceptibility varied depending on the welding parameters. Shorter cracks were observed at higher oscillation width and frequency conditions. As the oscillation width increased at an oscillation frequency of $100 \mathrm{~Hz}$, the specimen was less sensitive to hot cracking.

To evaluate the correlation between hot cracking susceptibility and bead shape, the details of the bead shape factors according to the laser beam oscillation parameters were analyzed and are presented in Table III and Fig. 7. In the correlation analysis [Table III] of the shape factor and hot cracking susceptibility, it was revealed that the bead width at the bottom surface $\left(a_{3}\right)$ and molten area $\left(s_{1}\right)$ were strongly correlated compared with the others. Meanwhile, the shape factors of $a_{1}$ and $a_{2}$ were independent of the oscillation width and frequency.

\section{B. Finite element modeling of laser beam oscillation welding}

A thermomechanical analysis was conducted to compare the stress fields at the start of solidification without oscillation (full penetration, FP) and at $200 \mathrm{~Hz}$ oscillation ( $0.8 \mathrm{~mm}$ oscillation width, partial penetration, PP). A conical volumetric heat source ${ }^{16,17}$ was employed to calculate the laser welding process as follows:

$$
\begin{gathered}
\dot{\mathrm{q}}^{\prime \prime \prime}=\frac{\delta 9 \eta P \exp (3)}{\pi(\exp (3)-1)} \cdot \frac{1}{C} \exp \left(-3\left(\frac{x^{2}+z^{2}}{r_{0}^{2}}\right)\right), \\
\mathrm{C}=\left(z_{T}+z_{B}\right)\left(r_{T}^{2}+r_{B}^{2}+r_{T} r_{B}\right), \\
r_{0}=r_{T}-\frac{\left(r_{T}-r_{B}\right)\left(z_{T}-z\right)}{z_{T}-z_{B}},
\end{gathered}
$$

where the $P$ and $\eta$ are laser power $(=2300 \mathrm{~W})$ and process efficiency $(=0.24)$, respectively. $z$ was treated as a moving coordinate with a $50 \mathrm{~mm} / \mathrm{s}$ welding speed, and $r_{i}$ and $z_{i}$ are the radii and heights of the heat source, respectively. The subscript $i$ represents the location of the heat source, the bottom (B) and the heat source top (T), as shown in Fig. 8(a). As shown in Fig. 9, for the case with an excessive volume of heat source on the weldment feature, the calculated heat amount of void volume will be missing while active volume is accounted. To avoid the volumetric mismatching problem, a volume loss compensation parameter, $\delta$, was employed in this study. The total volume and active volume were calculated using a commercial CAD program. For this study, the volume loss compensation parameters of the FP and PP cases were 1.8389 and 2.56 , respectively.

A schematic of the analysis domain is shown in Fig. 8(b). The heat source moves along the longitudinal direction ( $z$ direction). The minimum size of the mesh is $0.2 \times 0.2 \times 0.2 \mathrm{~mm}^{3}$. The gap between the top and bottom plate was considered to be $0.05 \mathrm{~mm}$-thick elements. Solving the conductive energy equation, the temperature history and distribution were calculated as follows:

$$
\rho C_{p} \frac{\partial T}{\partial t}=\frac{\partial}{\partial x}\left(k \frac{\partial T}{\partial x}\right)+\frac{\partial}{\partial y}\left(k \frac{\partial T}{\partial y}\right)+\frac{\partial}{\partial z}\left(k \frac{\partial T}{\partial z}\right)+\dot{\mathrm{q}}^{\prime \prime \prime},
$$

TABLE III. Laser welding conditions used in experiments.

\begin{tabular}{lcccccc}
\hline \hline Factor & $\mathrm{a}_{1}$ & $\mathrm{a}_{2}$ & $\mathrm{a}_{3}$ & $\mathrm{a}_{4}$ & $\mathrm{a}_{5}$ & $\mathrm{~s}_{1}$ \\
\hline Pearson correlation & 0.272 & -0.212 & $0.861^{*}$ & 0.491 & 0.740 & $0.818^{*}$ \\
Significantly change & 0.393 & 0.509 & 0 & 0.105 & 0.006 & 0.001 \\
\hline Model & Sum of squares & Degree of freedom & Mean square & R square & $\mathrm{F}$ & Significantly change \\
\hline Regression & 9044.241 & 1 & 9044.241 & 0.741 & 28.548 & 0.00 \\
Residual & 3168.072 & 10 & 316.807 & & & \\
Total & 12212.313 & 11 & & & & \\
\hline \hline
\end{tabular}




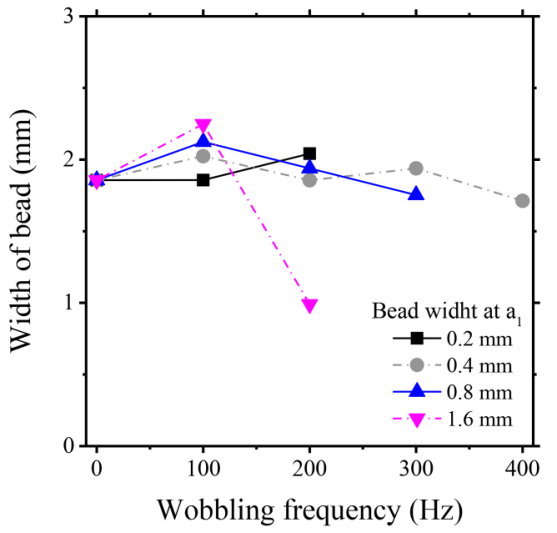

(a)

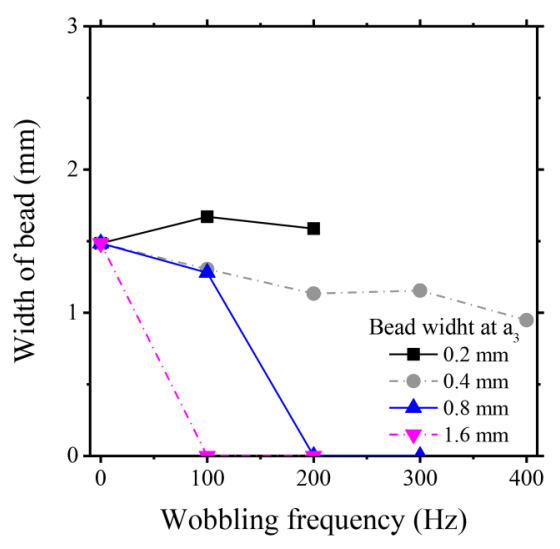

(c)

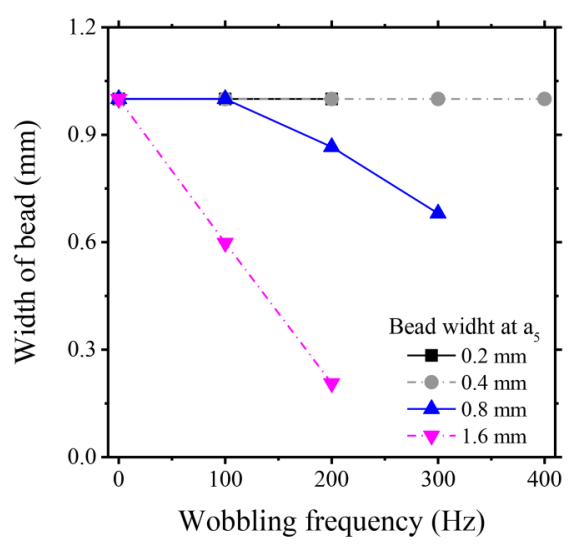

(e)

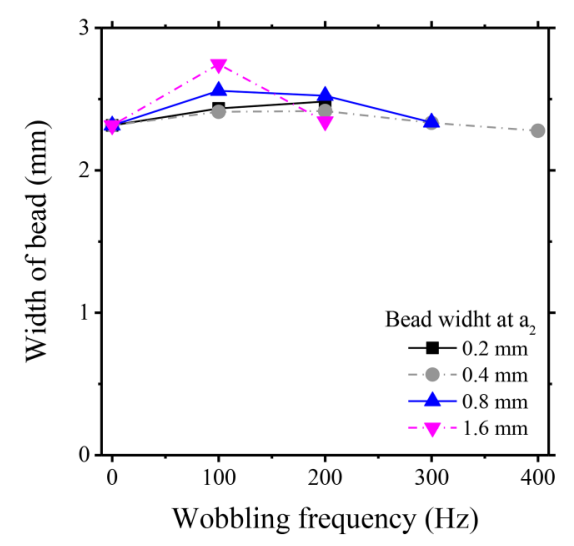

(b)

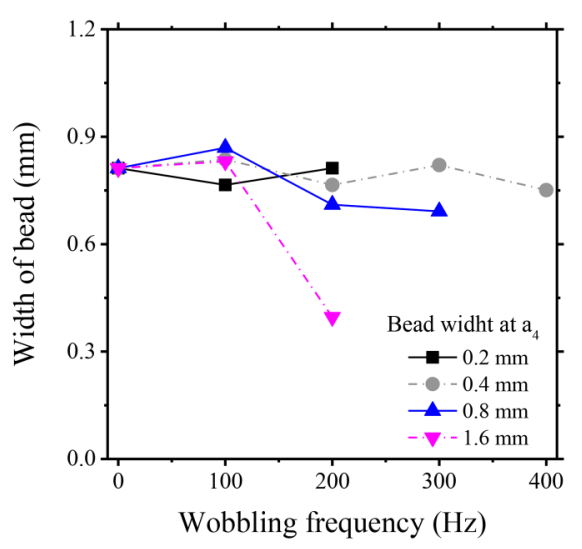

(d)

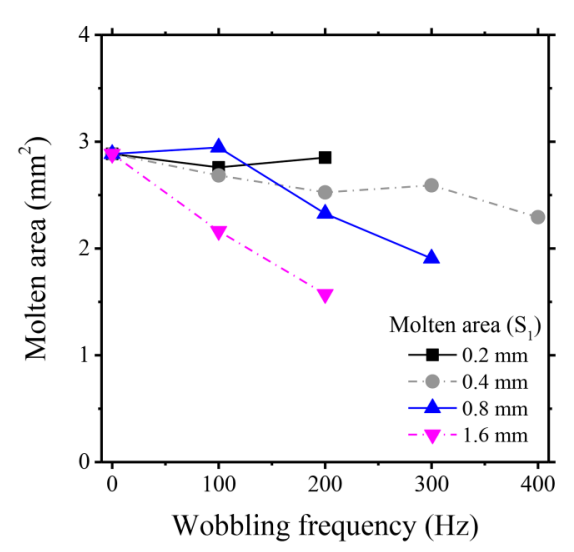

(f)
FIG. 7. Analysis of bead appearances according to the oscillation width and frequency. (a) Bead width at the interface $\left(a_{1}\right)$; (b) bead width at the top surface $\left(a_{2}\right) ;(c)$ thickness of the throat $\left(a_{3}\right) ;$ (d) bead width at the bottom surface $\left(a_{4}\right) ;(e)$ depth of the welds $\left(a_{5}\right) ;(f)$ : molten area $\left(s_{1}\right)$. where $T, \rho, C_{p}$, and $k$ are the temperature, density, specific heat, and conductive heat transfer coefficient, respectively. To reproduce the convective heat transfer effect, $k$ of the liquid state was treated as tripled value of ambient condition. The convective and radiated surface heat loss were considered with a $15 \mathrm{~W} / \mathrm{m}^{2}$ convective heat coefficient and 0.2 surface emissivity. The thermal properties ${ }^{18}$ are given in Table IV and Fig 10. 


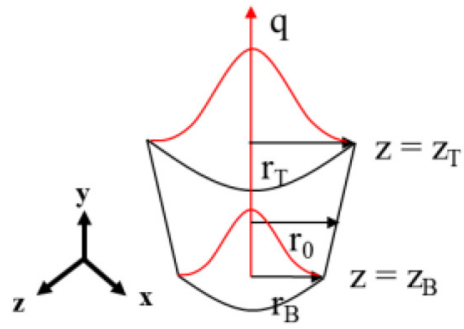

(a)

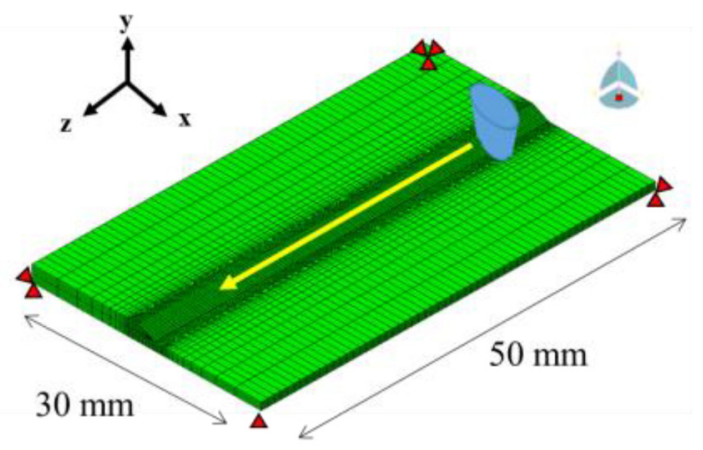

(b)

FIG. 8. (a) Schematic of conical volumetric heat source and (b) analysis domain.
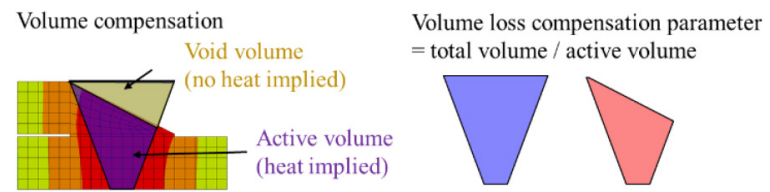

FIG. 9. Schematics of (left) volumetric mismatching and (right) volume loss compensation parameter.

TABLE IV. Temperature independent properties.

\begin{tabular}{cc}
\hline \hline Properties & Value \\
\hline Solidus temperature & $782.9 \mathrm{~K}$ \\
Liquidus temperature & $926.5 \mathrm{~K}$ \\
Density & $2700 \mathrm{~kg} / \mathrm{m}^{3}$ \\
Latent heat of fusion & $393 \mathrm{~kJ} / \mathrm{kg}$ \\
Effective thermal conductivity of liquid state & $501 \mathrm{~W} / \mathrm{mK}$ \\
\hline \hline
\end{tabular}

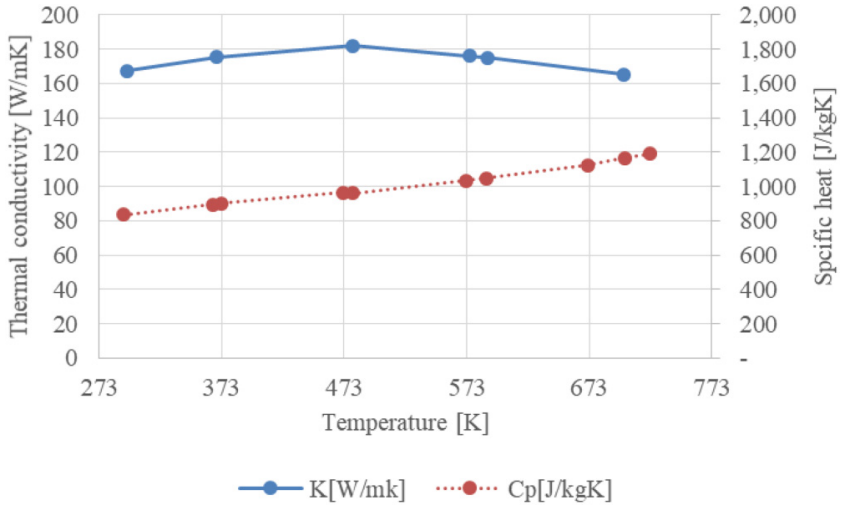

FIG. 10. Temperature dependent thermal conductivity and specific heat (Ref. 18).

The heat source size parameters, $r_{i}$ and $z_{i}$, were tuned by the trial and error method to fit the experimental fusion zone shape and size in Figs. 5(b) and 5(d) for the FP and PP cases, respectively. The fusion zone used for comparison was selected on the longitudinal half cross section of the analysis domain. The best fit condition is given in Fig. 11, and the corresponding heat source size parameters are given in Table V. The stress fields were calculated on the isotropic hardening model by the calculated thermal history (Fig. 12). The observed time, at the solidification start, was $5.5 \mathrm{~s}$ for both cases. The thermomechanical properties ${ }^{19}$ are given in Figs. 13 and 14.

\section{Stress distribution comparison between full penetration and partial penetration cases}

The Mises stress distributions on the cross section of the FP and PP cases at $5.5 \mathrm{~s}$ are displayed in Figs. 15(a) and 15(b), respectively. The FP case has a relatively uniform distribution of Mises

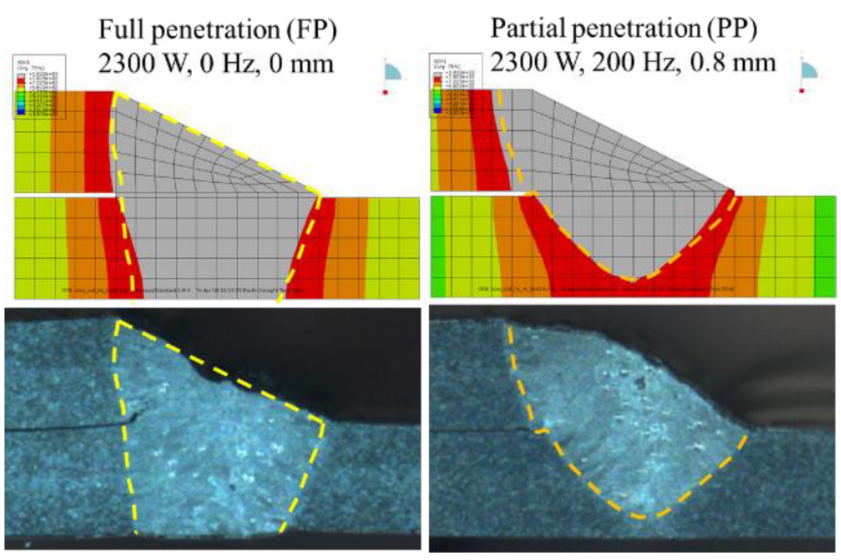

FIG. 11. Fusion zone comparison between thermal analysis and experiment. 
TABLE V. Conical volumetric heat source size parameters.

\begin{tabular}{lcccc}
\hline \hline$(\mathrm{mm})$ & $r_{T}$ & $r_{B}$ & $z_{T}$ & $z_{B}$ \\
\hline FP & 1.0 & 0.225 & 2.05 & 0 \\
PP & 1.6 & 0.425 & 2.05 & 0.8 \\
\hline \hline
\end{tabular}

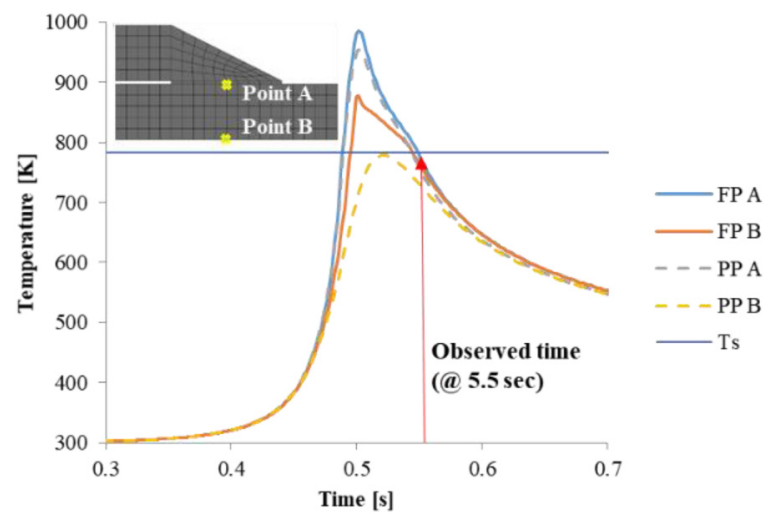

FIG. 12. Thermal histories of the FP case (solid line) and PP case (dashed line).

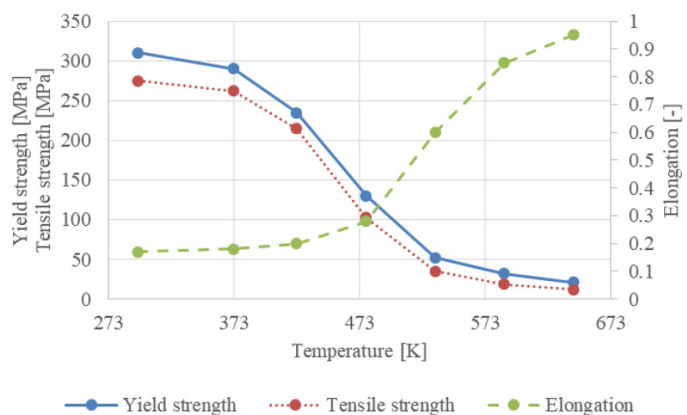

FIG. 13. Yield strength, tensile strength, and elongation (Ref. 19).

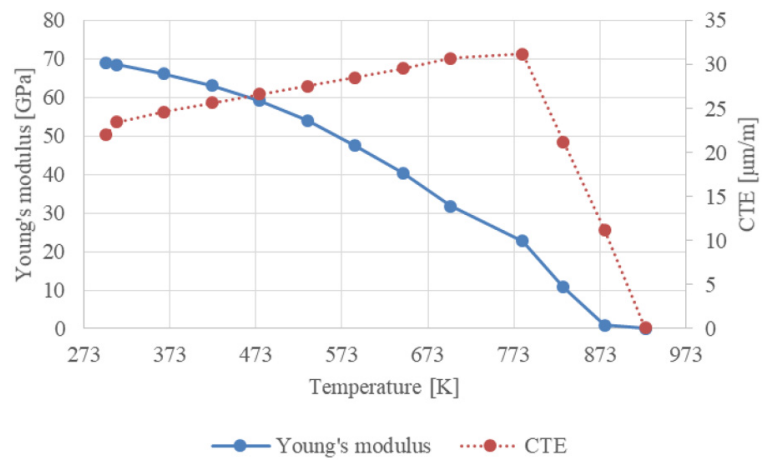

FIG. 14. Young's modulus and coefficient of thermal expansion (Ref. 18)
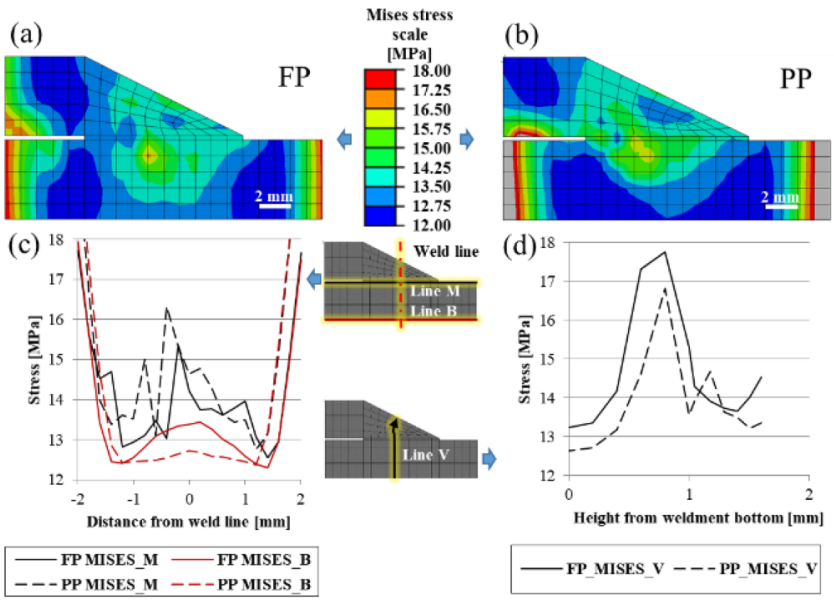

FIG. 15. Mises stress distribution in the (a) FP case, (b) PP case, (c) horizontal distribution on the middle line (line M) and bottom line (line B), and (d) vertical distribution on the vertical line (line V).

stress. However, the PP case has a high Mises stress on the middle and top while the bottom is low. As shown in Fig. 15(c), the horizontal stress distribution difference of the middle and bottom lines at the weld line have $2 \mathrm{MPa}$ for the PP case while the FP case has less than $1 \mathrm{MPa}$. The lower Mises stress concentration of the bottom of the PP case was caused by the relatively lower thermal history, which is below the solidus temperature. As a result, the vertical stress distribution [Fig. 15(d)] on the weld line in the PP case has a relatively lower stress level than the FP case. Therefore, a higher resistance to cracking could be expected in the PP case than in the FP case at the low strength state of high temperature.

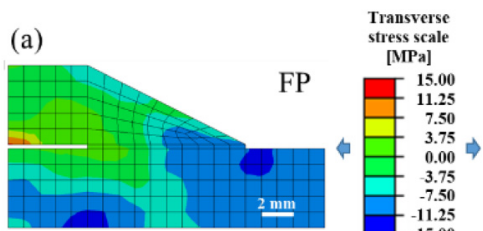

(b)
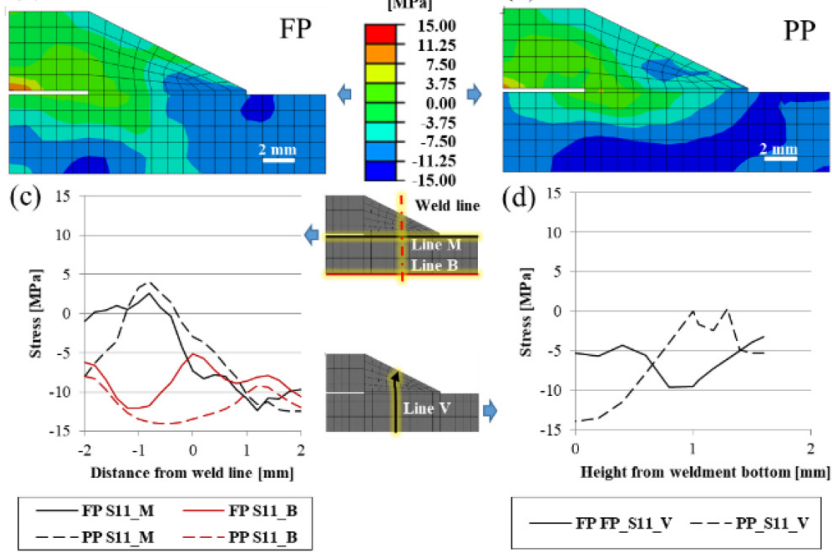

(d)

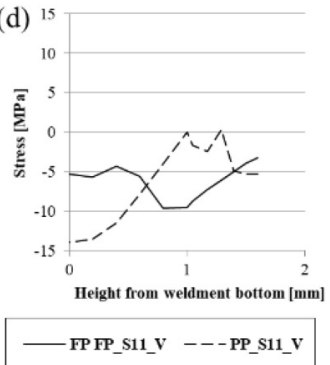

FIG. 16. Transverse stress distribution for the (a) FP case, (b) PP case, (c) horizontal distribution on the middle line (line M) and bottom line (line B), and (d) vertical distribution on the vertical line (line V). 
The transverse stress distributions on the cross section of the two cases are shown in Figs. 16(a) and 16(b). The FP has a vertically uniform stress distribution around the weld line, while the PP has a higher compression stress distribution on the weldment bottom. The vertical stress distribution of the PP can prevent the propagation of cracks, which can start at the top of the fusion zone, while the FP case cannot.

\section{CONCLUSION}

To evaluate hot cracking susceptibility, laser beam oscillation welding was performed on modified self-restraint test specimens with various oscillation frequencies and widths. The results showed that welding parameters influenced the hot cracking susceptibility. The penetration depth varied according to the oscillation width and frequency, and the length of solidification cracks was reduced with the decreasing width of the back bead.

In order to analyze the stress generated after the laser welding process, a laser heat source model was produced considering laser beam oscillations. Uniform Mises stress was distributed along the weld for the full penetration case, while the stress distribution was discontinuous in the partial penetration case. The difference in thermal history imposed on the specimen caused a heterogeneous stress field generation. As a result, it was demonstrated that a high shrinkage stress field at the bottom of the partial penetrated bead suppresses solidification cracking through the weld.

\section{ACKNOWLEDGMENTS}

The authors would like to acknowledge the funding and technical support provided by the Korea Institute of Industrial Technology and the Ministry of Trade, Industry, and Energy of the Republic of Korea. We also acknowledge the financial support provided through grants from the National Research Foundation of Korea (NRF), which is funded by the Ministry of Science and ICT (MSIT) (No. 2019R1F1A1042353).

\section{REFERENCES}

${ }^{1}$ M. Sheikhi, F. M. Ghaini, and H. Assadi, "Prediction of solidification cracking in pulsed laser welding of 2024 aluminum alloy," Acta Mater. 82, 491-502 (2015).

${ }^{\mathbf{2}} \mathrm{P}$. Von Witzendorff, S. Kaierle, O. Suttmann, and L. Overmeyer, "In situ observation of solidification conditions in pulsed laser welding of AL6082 aluminum alloys to evaluate their impact on hot cracking susceptibility," Metall. Mater. Trans. A 46, 1678-1688 (2015).

${ }^{3}$ H. Wei, J. Chen, H.-P. Wang, and B. E. Carlson, "Thermomechanical numerical analysis of hot cracking during laser welding of 6XXX aluminum alloys," J. Laser Appl. 28, 022405 (2016).
${ }^{4}$ V. Ploshikhin, A. Prikhodovsky, A. Ilin, M. Makhutin, C. Heimerdinger and F. Palm, "Influence of the weld metal chemical composition on the solidification cracking susceptibility of AA6056-T4 alloy," Weld. World 50, 46-50 (2006).

${ }^{\mathbf{5}} \mathrm{B}$. Hu and I. Richardson, "Mechanism and possible solution for transverse solidification cracking in laser welding of high strength aluminium alloys," Mater. Sci. Eng. A 9, 287-294 (2006).

${ }^{6}$ Y. Hiroto, Y. Masahiro, and T. Kazuyuki, "The study of prevention of solidification cracking in laser weld metal of Al-Mg-Si alloy," J. Jpn. Weld. Soc. 18, 422-430 (2000).

${ }^{7}$ L. Wang, M. Gao, C. Zhang, and X. Zeng, "Effect of beam oscillating pattern on weld characterization of laser welding of AA6061-T6 aluminum alloy," Mater. Des. 108, 707-717 (2016)

${ }^{8}$ H. Langrieger, F. Krafft, M. Mensinger, and F. Oefele, "Thermomechanical analysis of the formation of hot cracks in remote laser welded aluminium fillet welds," J. Laser Appl. 28, 022414 (2016).

${ }^{9}$ B.-H. Kim, N.-H. Kang, Y.-H. Park, Y.-N. Ahn, C.-H. Kim, and J.-H. Kim, “A study to improve weld strength of $\mathrm{Al} 6 \mathrm{k} 21-\mathrm{T} 4$ alloy by using laser weaving method," J. Weld. Joining 27, 49-53 (2009).

${ }^{10}$ K.-D. Choi, Y.-N. Ahn, and C. Kim, "Weld strength improvement for Al alloy by using laser weaving method," J. Laser Appl. 22, 116-119 (2010).

${ }^{11}$ K. Komerla, S. Gach, T. Vossel, A. Schwedt, A. Bührig-Polaczek, U. Reisgen, and W. Bleck, "The effect of beam oscillations on the microstructure and mechanical properties of electron beam welded steel joints," Int. J. Adv. Manuf. Technol. 102, 2919-2931 (2019).

${ }^{12} \mathrm{~S}$. Tsirkas, P. Papanikos, and T. Kermanidis, "Numerical simulation of the laser welding process in butt-joint specimens," J. Mater. Process. Technol. 134, 59-69 (2003).

${ }^{13}$ J. R. Chukkan, M. Vasudevan, S. Muthukumaran, R. R. Kumar, and N. Chandrasekhar, "Simulation of laser butt welding of AISI 316L stainless steel sheet using various heat sources and experimental validation," J. Mater. Process. Technol. 219, 48-59 (2015).

${ }^{14}$ S. Geng, P. Jiang, X. Shao, L. Guo, and X. Gao, "Heat transfer and fluid flow and their effects on the solidification microstructure in full-penetration laser welding of aluminum sheet," J. Mater. Sci. Technol. 46, 50-63 (2020)

${ }^{15}$ F. Matsuda and K. Nakata, "A new test specimen for self-restraint solidification crack susceptibility test of electron-beam welding bead: Fan-shaped cracking test," Trans. JWRI 11, 87-94 (1982).

${ }^{16}$ G. Agarwal, H. Gao, M. Amirthalingam, and M. Hermans, "Study of solidification cracking susceptibility during laser welding in an advanced high strength automotive steel," Metals 8, 673 (2018).

${ }^{17} \mathrm{C}$. Wu, H. Wang, and Y. Zhang, "A new heat source model for keyhole plasma arc welding in FEM analysis of the temperature profile," Weld. J. 85, 284-291 (2006).

${ }^{18} \mathrm{M}$. Awang, "Simulation of friction stir spot welding (FSSW) process: Study of friction phenomena," Ph.D. thesis, West Virginia University Libraries, 2007.

${ }^{19}$ E. L. Rooy, Introduction to Aluminum and Aluminum Alloys in ASM Metals Handbook Volume 02: Properties and Selection: Nonferrous Alloys and Special-Purpose Materials (ASM International, Materials Park, Ohio, 1990). 